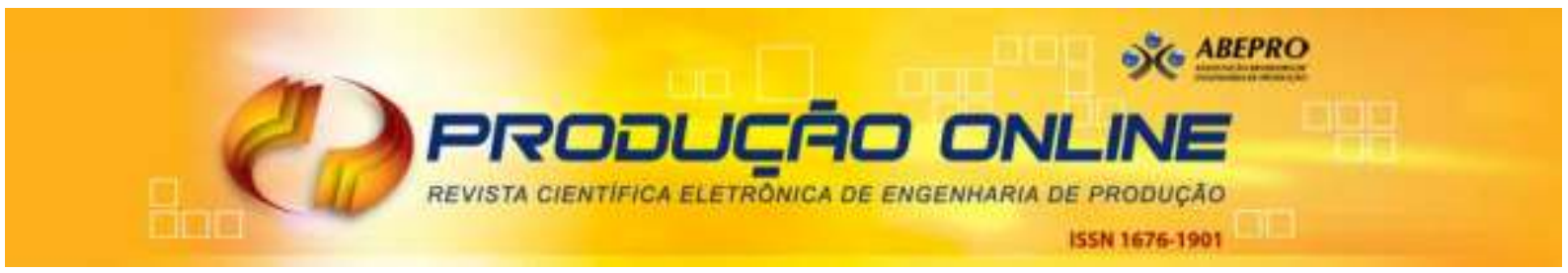

\title{
FATORES ERGONÔMICOS, PSICOSSOCIAIS E RISCOS NO TRABALHO NA MINERAÇÃO INFORMAL ${ }^{1}$
}

\section{ERGONOMIC, PSYCHOSOCIAL FACTORS AND RISKS AT WORK IN INFORMAL MINING}

\author{
Milena Nunes Alves de Sousa* E-mail: minualsa@hotmail.com \\ André Luiz Dantas Bezerra** Email: dr.andreldb@gmail.com \\ Branca Maria de Oliveira Santos*** Email: brancamosantos@yahoo.com.br \\ José Eduardo Zaia*** Email: zezaia@yahoo.com.br \\ Dernival Bertoncello**** Email: bertoncello@fisioterapia.uftm.edu.br \\ Paulo Roberto Veiga Quemelo*** Email: pqmelo@hotmail.com \\ *Faculdade Santa Maria e nas Faculdades Integradas de Patos, Paraíba (PB), Brasil \\ ${ }^{*}$ Socorrista do SAMU de Ibiara, Paraíba (PB), Brasil \\ ***Universidade de Franca, Franca, São Paulo (SP), Brasil \\ ****Universidade Federal do Triângulo Mineiro, Minas Gerais (MG), Brasil
}

\begin{abstract}
Resumo: Objetivou-se identificar os fatores ergonômicos, psicossociais e os riscos no trabalho informal no setor mineral do Estado da Paraíba sob a ótica de mineiros. Foi realizado um estudo descritivo e transversal. Participaram 371 trabalhadores informais da mineração, os quais responderam a dois questionários para analisar/avaliar o trabalho prestado em três dimensões: fatores ergonômicos; fatores psicossociais; e riscos ocupacionais. As pontuações dos itens de cada dimensão foram somadas de modo que, quanto maior a pontuação, menor a satisfação do trabalhador frente ao domínio investigado. Os resultados indicaram que o ruído muito alto é comum no ambiente laboral (66\%). A maioria (54,7\%) destacou que o trabalho era muito pesado e que exigia atenção e raciocínio $(85,7 \%)$. Os trabalhadores enfatizaram a falta de treinamentos para atuar na área $(59,3 \%)$ e poucos consideraram a manutenção do posto de trabalho como um dos componentes para se evitar a lombalgia $(32,3 \%)$. O risco de acidentes foi apontado como o fator de maior atenção no cotidiano laboral $(56,6 \%)$. Todos os riscos ocupacionais foram mencionados, destacando-se os físicos e químicos. Houve correlação significativa entre idade e os riscos ocupacionais, indicando que, quanto maior a idade, maior a percepção dos agentes nocivos ( $\rho=-$ $0,23 ; p<0,01)$. Ao final, constatou-se que todos os trabalhadores perceberam, em maior ou menor grau, os fatores ergonômicos, psicossociais e os riscos na mineração informal, sendo que o tempo de trabalho e a idade foram características que interferiram significativamente sobre o modo de perceber esses fatores e os riscos ocupacionais.
\end{abstract}

Palavras-chave: Trabalho. Saúde. Mineração. Ergonomia. Riscos Ocupacionais.

Abstract: The goal of this study was to identify ergonomic and psychosocial factors, and risks at informal work in the mining sector of the State of Paraíba, Brazil, from miners' perspective. A cross-sectional and

Artigo originado a partir de trabalho de tese de doutorado pelo Programa de Pós-Graduação Stricto Sensu em Promoção de Saúde da Universidade de Franca, Franca-SP, Brasil, desenvolvida sem fontes de financiamento, sem conflitos de interesse e aprovado pelo Comitê de Ética em Pesquisa da Universidade de Franca, parecer: 284.639.

Revista Produção Online, Florianópolis, SC, v.15, n. 3, p. 1099-1120, jul./set. 2015. 
descriptive study was conducted with 371 informal mining workers. They responded two questionnaires for assessing work performed in three dimensions: ergonomic factors; psychosocial factors; and occupational risks. The scores of the items of each dimension were added so that, the higher the score, the lower workers' satisfaction related to the area investigated. The results indicated that noise was common in the working environment (66\%). Most workers (54.7\%) pointed out that the work was too hard and that it required attention and reasoning (85.7\%). The workers emphasized the lack of training for working in mining (59.3\%) and few of them regarded the maintenance of the workplace as a component to prevent lumbago (32.3\%). Risk of accidents was pointed out as the factor that needed increased attention in daily work (56.6\%). All occupational risks were mentioned, including physical and chemical risks. There was significant correlation between age and occupational risks, indicating that the greater the age, the greater the perception of harmful agents $(\rho=-0.23 ; p<0.01)$. In the end, it was observed that, to a greater or lesser degree, all workers perceived ergonomic and psychosocial factors, and risks in informal mining. Length of service and age were the features that interfered significantly with the understanding of those factors and occupational risks.

Keywords: Work. Health. Mining. Ergonomics. Occupational Risks.

\section{INTRODUÇÃO}

A indústria mineral é aquela que contempla os trabalhos de pesquisa, extração de minerais a céu aberto e em subsolo, beneficiamento mineral, distribuição e comercialização dos produtos (BRASIL, 2009). A atividade no setor de mineração apresenta peculiar representatividade econômica, com movimentações financeiras significativas. Ao alcance de tais resultados, muitos trabalhadores inseridos no mercado de trabalho formal ou informal estão envolvidos nesse processo de trabalho (FALEIROS; LOPES, 2010; IBGE, 2007).

A atividade mineral apresenta grau de risco 4, conforme a Classificação Nacional de Atividades Econômicas (CNAE), em que os trabalhadores são expostos a riscos ocupacionais diversos, com alta capacidade de gerar danos para a sua saúde e segurança (BRASIL, 2009). Os riscos no setor são decorrentes das atividades insalubres e perigosas, que envolvem agentes biológicos, químicos, físicos ergonômicos e psicossociais. A exposição a todas as categorias de riscos ocupacionais, deixa-os mais propensos ao adoecimento (SEIDLER et al., 2014; KREUZER et al., 2013; LIU et al., 2013; NEGRI, 2012; SKANDFER et al., 2012; MOULIN; MORAES, 2010).

Contemplando os riscos ergonômicos, autores (COSTA et al., 2014; SOUSA et al., 2014; APUD, 2012; ELENGE; BROUWER, 2011; NERY; ALVES, 2011; SOUSA; ALCHIERI, 2011; DÍAZ; ABRIL; GARZÓN, 2010) destacam que sua presença na Revista Produção Online, Florianópolis, SC, v.15, n. 3, p. 1099-1120, jul./set. 2015. 
mineração parece inevitável, pois são comuns: exagerado esforço físico, uso continuado de escadas, quebra manual de pedras, elevação e carregamento de peso, utilização e transporte de ferramentas pesadas, posturas inapropriadas ao desempenhar o trabalho, tarefas desenvolvidas sobre máquinas e bancos inadequados, ritmos excessivos, trabalho monótono e repetitivo, jornadas prolongadas e trabalho em turnos. Tais peculiaridades corroboram com o surgimento de lesões, como as doenças osteomioarticulares relacionadas ao trabalho.

Em relação aos demais fatores de riscos, tem-se os de acidentes (pelas operações com veículos e máquinas, ambiente físico e processos organizacionais), os físicos (iluminação e ventilação inadequadas, temperaturas elevadas, umidade e ruído permanente), os químicos (exposição a poeira e contato com diversas substâncias químicas) e os biológicos (ambiente higiênico-sanitário deficiente e o manejo de águas não tratadas) (LENNÉ et al., 2012; ELENGE; BROUWER, 2011; NERY; ALVES, 2011; DÍAZ; ABRIL; GARZÓN 2010; MOULIN; MORAES, 2010; PATTERSON; SHAPPELL, 2010).

Camargo; Caetano; Guimarães (2005) e Iguti; Hoehne (2003) discutiram os riscos psicossociais na mineração, decorrentes das poucas possibilidades de alterar as condições laborais, falta de respeito e reconhecimento pelo trabalho, pressão e condições precárias no ambiente ocupacional, o que conduz ao estresse profissional e afeta a saúde mental e física dos mineiros. Os autores ainda enfatizaram a ocorrência de transtornos mentais e de comportamento, bem como o risco para o alcoolismo.

Ante as inúmeras situações de exposição os riscos ocupacionais na mineração, constata-se que os trabalhadores informais do setor estão mais susceptíveis aos riscos ocupacionais por estarem em maior número se comparados aos formais, bem como pela clandestinidade das atividades desempenhadas (COSTA; REZENDE, 2012). No estado da Paraíba, de acordo com o Departamento Nacional de Produção Mineral (DNPM, 2013), há 288 mineradoras e pedreiras regularizadas, com estimativas de existir pelo menos 600 outros pontos de mineração clandestina. Como problemática, tem-se que os trabalhadores informais, além da exposição rotineira aos riscos, vivenciam a precariedade no trabalho, sendo indicadores do labor inadequado: a falta 
de proteção social e de direitos trabalhistas gerais, a carga horária excessiva, a baixa remuneração e a mínima qualificação (HIRATA, 2009).

Notam-se, ainda, a ausência de equipamentos de proteção individual, a baixa formação escolar e profissional e a ausência de fiscalização das condições de trabalho nesses ambientes (COSTA; REZENDE, 2012; SARAIVA; FERREIRA; COIMBRA, 2012). Tais peculiaridades corroboram com o aumento da exposição aos riscos ocupacionais e, conseguintemente, com a maior probabilidade de agravos à saúde do grupo.

Pelas características laborais do trabalho informal na mineração, delineou-se o seguinte problema de pesquisa: quais os fatores ergonômicos, psicossociais e os riscos no trabalho percebidos pelos mineiros inseridos no mercado informal? Ante ao exposto, o presente estudo se justifica pela relevância e atualidade do tema. Skandfer et al. (2012) afirmam que, com o grande e crescente número de trabalhadores de minas, esta é uma temática de significativa relevância, especialmente ao trazer discussões que repercutem sobre a questões de saúde da população exposta.

Diante dos fatos e da escassez de estudos voltados aos trabalhadores informais da mineração, como se percebe em publicações da área (LENNÉ et al., 2012; ELENGE; BROUWER, 2011; NERY; ALVES' 2011; DÍAZ; ABRIL; GARZÓN, 2010; MOULIN; MORAES, 2010; PATTERSON; SHAPPELL, 2010), as quais contemplam especificamente os trabalhadores formais, o presente estudo tem como objetivo identificar os fatores ergonômicos, psicossociais e os riscos no trabalho informal no setor mineral do estado da Paraíba sob a percepção de mineiros, ou seja, do modo como cada um identifica os elementos presentes no ambiente ocupacional.

\section{MATERIAIS E MÉTODOS}

A pesquisa foi autorizada pelo Comitê de Ética em Pesquisa da Universidade de Franca, parecer: 284.639, de modo a atender os pressupostos da Resolução n 466/12 do Conselho Nacional de Saúde do Ministério da Saúde (BRASIL, 2013). Logo, caracterizou-se como de natureza descritiva, transversal, com abordagem quantitativa.

Revista Produção Online, Florianópolis, SC, v.15, n. 3, p. 1099-1120, jul./set. 2015. 
A natureza descritiva se baseia na compreensão do sentido das questões a que se voltam, evidenciando a opinião, a percepção das pessoas ao mesmo tempo em que quantifica os elementos mensuráveis de determinada realidade (ROUQUAYROL; GURGEL, 2013). Ainda para os autores, o estudo transversal se realiza a partir de dados obtidos em um momento pontual.

Quanto a abordagem quantitativa, Costa (2000) indica que este estudo é utilizado quando se tem um instrumento de medida utilizável, válido, se deseja objetividade e credibilidade dos achados, bem como a questão proposta indica a preocupação com a qualificação.

O estudo foi realizado no estado da Paraíba, com os trabalhadores informais da mineração da Região da Borborema-Seridó, a mais importante área extrativa mineral do estado, envolvendo 17 municípios.

Para a delimitação da amostra considerou-se um grau de confiança de $95 \%$ e margem de erro de $4,8 \%$, obtido com o auxílio do programa computacional DIMAM 1.0 (ARANGO, 2009), participando da pesquisa 371 trabalhadores. Entre os mineiros, a maioria era do sexo masculino $(93 \%)$, casada $(53,1 \%)$, com média de idade de $36,56 \pm 11,45$ anos, primeiro grau incompleto $(53,1 \%)$, renda de $874,12 \pm 315,33$ reais,

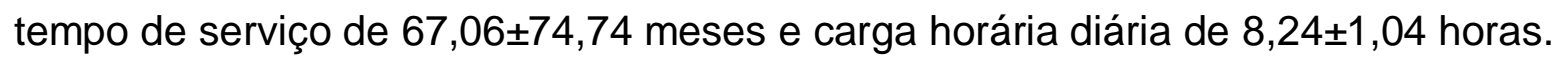

Os critérios de inclusão adotados foram: ser trabalhador informal do setor mineral, independentemente do nível de escolaridade, estar vinculado às cooperativas locais de extração mineral, ter 18 anos ou mais e aceitar voluntariamente participar da pesquisa, assinando o Termo de Consentimento Livre e Esclarecido. Excluíram-se os mineiros que atuavam na mineração há menos de 12 meses e os que estavam de licença de saúde ou ausente do trabalho no período de coleta (entre agosto de 2013 e junho de 2014).

Os instrumentos de coleta de dados utilizados foram os questionários adaptados de Costa (2012) e Pontes (2005). Costa (2012) propôs um instrumento que avalia os riscos ocupacionais (físicos, químicos, biológicos, ergonômicos e de acidentes) e o de Pontes (2005) a análise dos fatores ergonômicos que podem interferir no trabalho, tais como o ambiente de trabalho (iluminação, temperatura, ruído, circulação e cor), carga 
de trabalho (exigências laborais, peso do trabalho, atenção e raciocínio, pressão horário, tempo de função, supervisão, horas extras e existência de treinamentos) e manutenção do posto de trabalho (manutenção em geral, auxílio na manutenção do posto de trabalho, compartilhamento das tarefas, treinamentos e associação entre manutenção do seu posto de trabalho e doenças). Também, pondera sobre os fatores psicossociais, contemplando os sentimentos em relação ao trabalho, respeito e fator que prende maior atenção ao realizar as tarefas.

Os instrumentos contemplaram a satisfação em três dimensões do trabalho (fatores ergonômicos - ambiente de trabalho, carga de trabalho, manutenção do posto de trabalho; fatores psicossociais e riscos ocupacionais do trabalho). Os itens que compuseram as dimensões variaram de 1 para Sim e 0 para Não. As pontuações dos itens de cada dimensão foram somadas de modo que quanto maior a pontuação menor a satisfação ou percepção de adequação do trabalhador frente ao domínio investigado. Este procedimento de análise foi proposto pelos pesquisadores desta investigação, visto que os autores dos instrumentos utilizados adotaram apenas a estatística simples para tabulação de seus achados.

A análise dos dados foi efetivada por meio da estatística descritiva simples e inferencial. Na primeira, foram realizados o cálculo da média, mediana, desvio padrão (DP), valores máximos e mínimos, frequências relativas (fr) e absolutas (Fi). Quanto a inferencial, utilizou-se o coeficiente de correlação de Spearman para verificar a correlação entre fatores ergonômicos, psicossociais, riscos ocupacionais, idade e tempo de trabalho. Os dados foram processados no programa Statistical Package for the Social Sciences (SPSS), versão 21.0. Ressalta-se que o nível de significância adotado foi de $p \leq 0,05$. 


\section{RESULTADOS}

\subsection{Fatores Ergonômicos do Trabalho}

A tabela 1 apresenta as respostas dos trabalhadores às questões referentes aos fatores ergonômicos do trabalho, contemplando ambiente de trabalho, carga de trabalho e manutenção do posto de trabalho. No ambiente laboral constata-se que $66 \%$ $(n=245)$ consideraram que o nível de ruído era muito alto. Em relação à carga de trabalho, mais da metade $(54,7 \% ; n=203)$ considerou que o trabalho é muito pesado e $85,7 \%$ ( $n=318$ ) que exige muita atenção e raciocínio. As respostas dos sujeitos em relação à manutenção do posto de trabalho, em que $67,7 \%(n=251)$ dos trabalhadores não a consideram como um dos componentes para se evitarem lombalgia. Outro dado relevante relaciona-se à falta de treinamentos para trabalhar na área $(59,3 \% ; n=220)$ (Tabela 1). 
Tabela 1 - Distribuição dos fatores ergonômicos do trabalho

\begin{tabular}{|c|c|c|c|}
\hline Ambiente de trabalho & & $\mathbf{n}$ & $\%$ \\
\hline \multirow{2}{*}{ Você considera a iluminação do ambiente de trabalho adequada? } & Sim & 348 & 93,8 \\
\hline & Não & 23 & 6,2 \\
\hline \multirow{2}{*}{ Você considera a temperatura do ambiente de trabalho adequada? } & Sim & 262 & 70,6 \\
\hline & Não & 109 & 29,4 \\
\hline \multirow{2}{*}{ Você considera o nível de ruído no ambiente de trabalho muito alto? } & Sim & 245 & 66,0 \\
\hline & Não & 126 & 34,0 \\
\hline \multirow{2}{*}{ Você considera a área de circulação adequada? } & $\operatorname{Sim}$ & 316 & 85,2 \\
\hline & Não & 55 & 14,8 \\
\hline \multirow{2}{*}{ A cor do ambiente de trabalho é estressante para você? } & Sim & 167 & 45,0 \\
\hline & Não & 204 & 55,0 \\
\hline Carga de trabalho & & $\mathbf{n}$ & $\%$ \\
\hline \multirow{2}{*}{ As exigências impostas pelo trabalho são muito difíceis para você? } & Sim & 98 & 26,4 \\
\hline & Não & 273 & 73,6 \\
\hline \multirow{2}{*}{ O trabalho que você executa diariamente é muito pesado? } & Sim & 203 & 54,7 \\
\hline & Não & 168 & 45,3 \\
\hline \multirow{2}{*}{ O trabalho que você executa exige muita atenção e raciocínio? } & Sim & 318 & 85,7 \\
\hline & Não & 52 & 14,0 \\
\hline \multirow{2}{*}{$\begin{array}{l}\text { Existe algum tipo de pressão que você recebe que torna seu trabalho } \\
\text { mais pesado? (Horário, tempo de função, supervisão etc.)? }\end{array}$} & Sim & 115 & 31,0 \\
\hline & Não & 255 & 68,7 \\
\hline \multirow{2}{*}{ As horas extras são frequentes na sua atividade? } & Sim & 122 & 32,9 \\
\hline & Não & 248 & 66,8 \\
\hline \multirow{2}{*}{$\begin{array}{l}\text { Você recebeu algum tipo de treinamento que tornou seu trabalho mais } \\
\text { leve operacionalmente? }\end{array}$} & Sim & 132 & 35,6 \\
\hline & Não & 239 & 64,4 \\
\hline Manutenção do posto de trabalho & & $\mathbf{n}$ & $\%$ \\
\hline \multirow{2}{*}{$\begin{array}{l}\text { O ambiente de trabalho possui setor específico para manutenção em } \\
\text { geral? }\end{array}$} & Sim & 242 & 65,2 \\
\hline & Não & 129 & 34,8 \\
\hline \multirow{2}{*}{ Você auxilia na manutenção do seu posto de trabalho? } & Sim & 193 & 52,0 \\
\hline & Não & 178 & 48,0 \\
\hline \multirow{2}{*}{$\begin{array}{l}\text { A manutenção e a limpeza do posto de trabalho são compartilhadas } \\
\text { com todos os seus colegas }\end{array}$} & Sim & 203 & 54,7 \\
\hline & Não & 168 & 45,3 \\
\hline \multirow{2}{*}{$\begin{array}{l}\text { Você recebeu treinamento para fazer reparos no seu posto de trabalho, } \\
\text { incluindo máquinas e equipamentos? }\end{array}$} & Sim & 151 & 40,7 \\
\hline & Não & 220 & 59,3 \\
\hline \multirow{2}{*}{$\begin{array}{l}\text { Você considera a manutenção do posto de trabalho como um dos } \\
\text { componentes para se evitarem lombalgia, por exemplo? }\end{array}$} & Sim & 120 & 32,3 \\
\hline & Não & 251 & 67,7 \\
\hline
\end{tabular}

Fonte: Pesquisa direta, 2013/2014

\subsection{Fatores Psicossociais do Trabalho}

A tabela 2 apresenta que os trabalhadores se sentem à vontade (descontraído, com naturalidade) dentro do seu trabalho $(76 \% ; n=282)$, além de se sentirem respeitados $(93,8 \% ; n=348)$. Consideram que os riscos de acidentes é o fator que prende maior atenção no cotidiano do trabalho do setor extrativista mineral (56,6\%; $\mathrm{n}=210)$ (Tabela 2).

Revista Produção Online, Florianópolis, SC, v.15, n. 3, p. 1099-1120, jul./set. 2015. 
Tabela 2 - Distribuição dos fatores psicossociais do trabalho

\begin{tabular}{lccc}
\hline \multicolumn{1}{c}{ Fatores psicossociais do trabalho } & $\mathbf{n}$ & $\%$ \\
\hline Como você se sente dentro de seu trabalho? & $\begin{array}{c}\text { À vontade } \\
\text { (descontraído, com } \\
\text { naturalidade) }\end{array}$ & 282 & 76,0 \\
& Muito bem & 75 & 20,2 \\
\hline Você se acha respeitado como um bom profissional? & Retraído & 6 & 1,6 \\
\hline & Pressionado & 7 & 1,9 \\
\hline
\end{tabular}

Fonte: Pesquisa direta, 2013/2014

\subsection{Riscos Ocupacionais no Trabalho}

A tabela 3 ilustra os fatores de riscos presentes no ambiente laboral. Os dois tipos mais frequentes foram os físicos $(72,5 \% ; n=269)$ e os químicos $(71,2 \% ; n=264)$, ainda que os riscos ergonômicos e de acidentes tenham sido relatados por 50,7\% $(n=188)$ e $66,8 \%(n=248)$ mineiros, respectivamente (Tabela 3).

Tabela 3 - Distribuição dos riscos ocupacionais presentes no ambiente de trabalho

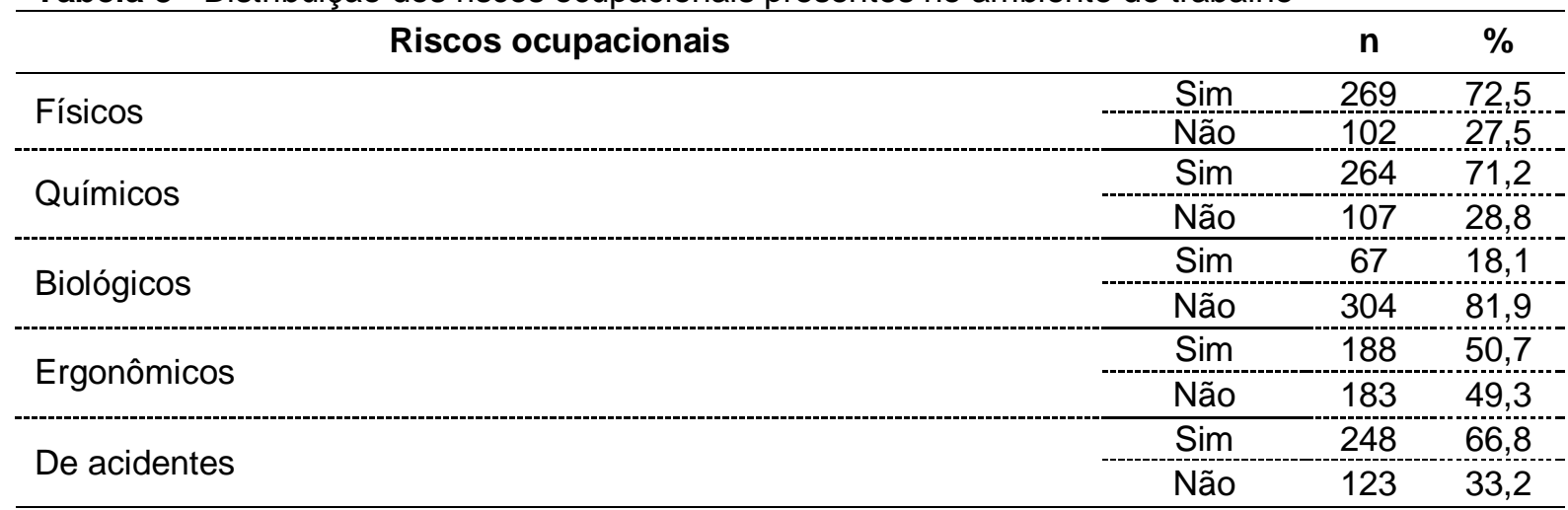

Fonte: Pesquisa direta, 2013/2014

A tabela 4 apresenta a média, mediana e o desvio padrão dos escores dos fatores ergonômicos, psicossociais e riscos ocupacionais. Quanto maiores as médias e

Revista Produção Online, Florianópolis, SC, v.15, n. 3, p. 1099-1120, jul./set. 2015. 
medianas piores as percepções dos domínios da ergonomia e dos riscos do trabalho. $\mathrm{O}$ ambiente de trabalho foi o fator ergonômico mais comprometido e a presença dos riscos ocupacionais apresentou relevância (Tabela 4).

Tabela 4 - Sumário estatístico dos fatores ergonômicos, psicossociais e riscos ocupacionais

\begin{tabular}{|c|c|c|c|c|c|}
\hline \multirow[b]{2}{*}{ Medidas descritivas } & \multicolumn{3}{|c|}{ Fatores ergonômicos } & \multirow[b]{2}{*}{$\begin{array}{c}\text { Fatores } \\
\text { psicossociais }\end{array}$} & \multirow[b]{2}{*}{$\begin{array}{c}\text { Riscos } \\
\text { ocupacionais }\end{array}$} \\
\hline & $\begin{array}{l}\text { Ambiente de } \\
\text { trabalho }\end{array}$ & $\begin{array}{l}\text { Carga de } \\
\text { trabalho }\end{array}$ & $\begin{array}{l}\text { Manutenção } \\
\text { do posto de } \\
\text { trabalho }\end{array}$ & & \\
\hline Média & 3,60 & 2,68 & 2,45 & 0,35 & 2,79 \\
\hline Mediana & 4,00 & 2,00 & 3,00 & 0,00 & 3,00 \\
\hline Desvio padrão & 1,14 & 1,57 & 1,67 & 0,69 & 1,35 \\
\hline Mínimo & 0,00 & 0,00 & 0,00 & 0,00 & 0,00 \\
\hline Máximo & 5,00 & 6,00 & 5,00 & 4,00 & 4,00 \\
\hline
\end{tabular}

Fonte: Pesquisa direta, 2013/2014

$\mathrm{Na}$ tabela 5 é possível perceber a correlação negativa e significativa entre idade e ambiente de trabalho $(\rho=-0,18 ; p<0,01)$. Correlação significativa positiva foi encontrada entre idade e os riscos ocupacionais $(\rho=0,23 ; p<0,01)$. Estes também se correlacionaram positivamente com o tempo de trabalho $(\rho=0,14 ; p<0,01)$. Além disso, o tempo de trabalho se correlacionou positivamente com os fatores psicossociais $(\rho=$ $0,14 ; p<0,05)$ (Tabela 5).

Tabela 5 - Correlação entre fatores ergonômicos, psicossociais, riscos ocupacionais, idade e tempo de trabalho

\begin{tabular}{|c|c|c|c|c|}
\hline \multicolumn{2}{|c|}{ Variáveis } & Idade & $\begin{array}{l}\text { Tempo de } \\
\text { trabalho }\end{array}$ & $\begin{array}{l}\text { Jornada } \\
\text { diária }\end{array}$ \\
\hline \multirow{3}{*}{ Fatores ergonômicos } & Ambiente de trabalho & $-0,18$ & 0,05 & $-0,03$ \\
\hline & Carga de trabalho & 0,03 & 0,01 & $-0,01$ \\
\hline & $\begin{array}{l}\text { Manutenção do posto de } \\
\text { trabalho }\end{array}$ & 0,08 & 0,07 & $-0,02$ \\
\hline Fatores psicossociais & & $-0,04$ & 0,14 & 0,01 \\
\hline Riscos ocupacionais & & $0,23^{\text {en }}$ & $0,14^{* * x}$ & $-0,07$ \\
\hline
\end{tabular}

Fonte: Pesquisa direta, 2013/2014

${ }^{*} p<0,05 ;{ }^{* *} p<0,01$ de acordo com Correlação de Spearman.

Revista Produção Online, Florianópolis, SC, v.15, n. 3, p. 1099-1120, jul./set. 2015. 


\section{DISCUSSÃO}

Os resultados possibilitaram identificar os fatores ergonômicos (ambiente de trabalho, carga de trabalho e manutenção do posto de trabalho) e psicossociais mais comprometidos no setor de mineração em análise, bem como os riscos ocupacionais presentes na atividade. $\mathrm{O}$ ambiente de trabalho adequado, do ponto de vista funcional,

é capaz de corroborar satisfatoriamente com o desempenho das atividades com qualidade e eficiência (PIERANTONI et al., 2011).

A maioria dos pesquisados considerou que o ruído no ambiente de trabalho era muito alto. A exposição a tal agente advém das características do processo de trabalho na região, afinal, ainda é comum a utilização de equipamentos obsoletos e barulhentos. A própria atividade mineral em si (quebra de pedra, abertura de valas, uso de explosivos, etc.) conduz à maior exposição ao ruído intenso. Soma-se a esta situação o não uso de protetores auriculares pela maioria trabalhadora desta investigação. Semelhante a esta abordagem, outras pesquisas (NERY; ALVES, 2011; DÍAZ; ABRIL; GARZÓN, 2010; MOULIN; MORAES, 2010) têm observado que o ruído é considerado uma das causas mais comuns de doença profissional.

Atentando para os ruídos presentes no cotidiano do trabalho dos mineiros, é preciso criar estratégias para adequá-los ao padrão normal e evitar efeitos negativos sobre a saúde dos trabalhadores, como a perda auditiva (CAVALCANTE; FERRITE; MEIRA, 2013). Conforme discorrem Rodrigues et al. (2009), a avaliação do nível de ruído gerado durante o exercício laboral é uma ação estratégica importante, para que seja possível adotar medidas preventivas, afinal, a perda auditiva é irreversível e onerosa para o Sistema Único de Saúde.

Os resultados do presente estudo evidenciaram que $54,7 \%$ dos trabalhadores informais da mineração referiram que o trabalho era muito pesado e $85,7 \%$ que o mesmo exigia muita atenção e raciocínio. As atividades desempenhadas no setor apresentam demanda física intensa, com posições inadequadas. Considerando as altas taxas de acidentes na localidade, os trabalhadores rotineiramente executam as tarefas 
preocupados com a probabilidade de desmoronamentos e mortes, o que os deixa atentos.

A carga de trabalho é discutida como um elemento que interatua entre o trabalhador e o trabalho, o qual pode refletir em desgaste, contemplando a carga física, psíquica e mental (MOTTER; SANTOS; GUIMARÃES, 2015; PIERANTONI et al., 2011). Estudos desenvolvidos objetivando abordar as cargas de trabalho em distintas áreas trazem resultados, em decorrência das transformações nas esferas produtivas, que alertam para o excesso de carga de trabalho no cotidiano laboral dos trabalhadores (MOTTER; SANTOS; GUIMARÃES, 2015; MARTINS et al., 2013; APUD; MEYER, 2011; PIERANTONI et al., 2011). Pesquisas também têm concluído que a elevada demanda mental contribui para a ocorrência de doenças osteomusculares (FERNANDES; ASSUNÇÃO; CARVALHO, 2010), bem como esforços físicos, levantamento de peso e a má postura (KUNDA; FRANTZ; KARACHI, 2013; SOLARI; REYES; SOLARI, 2009).

Em relação à manutenção do posto de trabalho, 32,3\% dos trabalhadores relataram que a mesma é um dos componentes para se evitar a lombalgia. Tal resultado, insatisfatório, pode relacionar-se ao fato de a maioria dos trabalhadores $(59,3 \%)$ não ter recebido treinamento para trabalhar na área, aprendendo no dia a dia, pois são treinados de forma empírica, a partir da execução das tarefas no próprio local de trabalho. Como neste estudo, Mauro et al. (2010) identificaram que muitos trabalhadores demonstram carência total ou parcial de informação e conhecimento sobre os fatores ergonômicos, o que remete à necessidade de treinamentos específicos a fim de transformar hábitos dos trabalhadores com vistas à adotarem medidas que melhor adaptem o homem ao trabalho.

Receber orientações sobre os princípios da ergonomia no trabalho de mineração parece oportuno, pois Mcphee (2004) considera que é pobre a compreensão da contribuição desta ciência na área, considerando-se desde as transformações nas práticas laborais até as benfeitorias na produtividade. Solari; Reyes; Solari (2009) afirmam que a ergonomia oferece alternativas com rigor científico que permitem uma 
gestão terapêutica e profilática adequada para minimizar os efeitos nocivos de patologias relacionadas ao trabalho no setor mineral.

O ambiente de trabalho foi o aspecto com maior necessidade de atenção, representando a pior percepção entre os domínios da ergonomia. Este resultado talvez possua relação com o lócus de extração (lavra) dos minérios, em geral, no subsolo, em espaços com pouca luz e ventilação, oportunizando a ocorrência de acidentes, gerando incapacidades e até morte. Estudo sobre os acidentes nas minas de carvão da região carbonífera de Santa Catarina, entre os anos de 1980 a 2000, destaca que os acidentes com perdas fatais são comuns neste setor (FELIPE, 2013). Vasconcelos; Vasconcelos; Moraes Neto (2013), em investigação sobre os riscos ambientais causados na extração mineral em atividade a céu aberto no município de Pedra Lavrada/PB, constataram que o risco de acidente foi o mais comum. O risco estava presente em todas as operações que envolviam o garimpo local.

Pelas exposições, são necessárias priorizações, contemplando adoção de medidas de segunça e saúde na atividade. Propiciar adequações nas condições de trabalho e na infraestrutura das minas, bem como utilizar adequadamente os equipamentos de proteção individual e de proteção coletiva podem diminuir os agravantes relacionados aos riscos de acidentes.

Os fatores psicossociais são considerados, como fatores imateriais do trabalho e pouco contemplados nas pesquisas sobre riscos ocupacionais (RUIZ; ARAÚJO, 2012). Os achados para esse fator mostraram-se satisfatórios para o presente estudo, pois indicaram que os trabalhadores não apresentaram conflitos interpessoais nas relações de trabalho, sentindo-se à vontade com o trabalho, bem como respeitado no grupo. Contudo, um elemento apresentou-se insatisfatório, com $56,6 \%$ da amostra de mineiros apontando os riscos de acidentes como o fator que prende maior atenção no cotidiano do trabalho no setor extrativista mineral, exigindo importante concentração. Aerosa (2014) coloca que cada categoria profissional possui seu próprio "portfólio" de riscos ocupacionais e que tais fatores são percebidos, entendidos e decodificados de modos distintos. $O$ dado possivelmente tem relação com o fato de serem comuns os acidentes 
na área, com óbitos consideráveis, como vários estudos elucidam (FELIPE, 2013; VASCONCELOS; VASCONCELOS; MORAES NETO, 2013; NERY; ALVES, 2011).

Em geral, na atividade de extração mineral, os problemas estão ligados à segurança e saúde dos trabalhadores, como as condições precárias de trabalho em que não há vigas de sustentação, nem escoramento, o que gera insegurança em termos de desmoronamento das mesmas. A iluminação no local geralmente pode ser realizada por meio de velas, cujo uso muitas vezes serve para indicar a quantidade de oxigênio presente no ar, possibilitando a maior exposição aos riscos de acidentes e morte.

Todos os riscos ocupacionais foram mencionados pelos mineiros, contudo, os agentes nocivos do ambiente de trabalho mais frequentes foram os físicos $(72,5 \%)$ e os químicos $(71,2 \%)$. Este resultado reflete a preocupação de cada trabalhador, a qual é influenciada pela vivência de cada um, pelo nível de escolaridade, pela cultura, entre outros. De modo análogo, a literatura busca esclarecimentos para as razões pelas quais alguns indivíduos valorizam mais ou menos certos tipos de riscos. Aerosa (2014, p. 85) tenta explicar tal fenômeno. Para o autor, pode advir das informações e conhecimentos adquiridos ao longo da vida, das representações sociais sobre determinadas situações, medos intrínsecos e histórias de vida. "As perceções de riscos estão interligadas com o nosso conhecimento sobre a realidade envolvente e com as nossas experiências vivenciais".

Semelhantemente a este, muitos estudos abordam os riscos presentes no processo de trabalho na mineração (IGWE et al., 2014; PASCAUD et al., 2014; KREUZER et al., 2013; LIU et al., 2013; STEFANESCU; ROBU; OZUNU, 2013; VASCONCELOS; VASCONCELOS; MORAES NETO, 2013; NERY; ALVES, 2011; DÍAZ; ABRIL; GARZÓN, 2010; MOULIN; MORAES, 2010), mas parte das pesquisas na área limita-se a explorar os efeitos dos riscos químicos, ou seja, da exposição dos trabalhadores a poeiras, fumos, névoas, neblinas, gases, vapores e substâncias, compostos ou produtos químicos em geral. Enfatizam que à exposição a poeira de sílica é determinante para o surgimento da silicose e demais pneumoconioses (KREUZER et al., 2013; LIU et al., 2013).

Revista Produção Online, Florianópolis, SC, v.15, n. 3, p. 1099-1120, jul./set. 2015. 
As inquietações em torno da exposição aos agentes químicos podem ter relação com a falta de equipamentos adequados para proteção dos trabalhadores, possibilitando a inalação de partículas sólidas muito pequenas de poeira, cuja exposição durante um longo período pode provocar doenças no sistema respiratório dos trabalhadores e levá-los a morte.

Os agentes físicos, como ruídos, vibrações, altas e baixas temperaturas, pressões anormais, radiação ionizante e não ionizante, umidade e luminosidade foram relatados em outras abordagens também (AEROSA, 2014; NERY; ALVES, 2011; DÍAZ; ABRIL; GARZÓN, 2010; MOULIN; MORAES, 2010), reconhecendo que "os agentes físicos, sempre que possível, devem ser definidos quantitativamente: em decibéis, lux, medidas de temperatura e outros" (GANIME et al., 2010, p. 6), a fim de controlar o limite de exposição tolerável pelo ser humano, evitando agravos como perda auditiva induzida por ruído, neoplasias, estresse, fadiga e outros.

Foi observado que a idade se correlacionou negativamente com fatores ergonômicos indicando uma maior percepção quanto a estes fatores à medida que a idade avança. Acredita-se que o resultado deva-se ao fato de que com o progredir da idade e os anos de experiência, os indivíduos passem a possuir maior percepção das inadequações dos fatores ergonômicos e, conseguintemente, identifiquem mais apropriadamente as condições impróprias do lócus de trabalho. Esta particularidade reveste-se de relevância, visto que a redução ou eliminação dos riscos depende do modo como se percebe a susceptibilidade, deste modo, o trabalhador é capaz de auxiliar na melhoria das condições ambientais e de saúde, pois como realiza o trabalho diariamente, deve conhecê-lo e reconhecer as situações capazes de colocar em risco sua integridade. Cabe ao mineiro tornar-se "[...] protagonista na identificação, controle e eliminação dos riscos ambientais e participante nas ações e planos que busquem melhores condições de saúde-trabalho" (SANTO; PAULA; PEREIRA, 2009, p. 190).

Houve correlação significativa entre idade e os riscos ocupacionais, com correlação positiva, indicando que quanto maior a idade maior a percepção dos agentes nocivos. Tais dados podem relacionar-se com a experiência adquirida com os anos de trabalho, em que o trabalhador adquire conhecimento técnico e se apropria do modo de 
execução de suas tarefas, passando a refletir mais apropriadamente sobre os fatores geradores de adoecimento na atividade ocupacional. O achado tem implicações na adoção ou não de atos inseguros, pois uma das variáveis relacionada a insegurança no trabalho, fator contribuinte de acidentes, é a percepção dos riscos pelo trabalhador (KOROLIJA; LUNDBERG, 2010).

Contudo, os riscos ocupacionais se correlacionaram negativamente com o tempo de trabalho, mostrando que quando mais tempo na ocupação menor a percepção de agentes nocivos. Acredita-se que o resultado deva-se ao fato de que com o tempo de ocupação, os indivíduos acostumam-se com o lócus de trabalho e passam a tolerar mais as inadequações do mesmo. Afinal, a precarização dos vínculos laborais é uma realidade na localidade e tem implicações sobre a origem dos agravos decorrentes das relações laborais. Considerando a precariedade advinda da informalidade, melhor seria desenvolver estratégias adaptativas, como parecem fazê-las.

É positiva e apresenta importância considerável esta capacidade de adaptabilidade dos indivíduos às diversas situações no ambiente laboral, buscando assegurar um espaço de convivência saudável, satisfatório e motivador para o trabalho, superando as adversidades, pois evita descompensações de ordem física e mental. Piovan (2012) reforça que este processo adaptativo provém das situações adversas que os indivíduos já vivenciaram, assim sendo, as pessoas fazem mudanças em suas atitudes e forma de perceber o mundo.

O tempo de trabalho também se correlacionou negativamente com os fatores psicossociais, advertindo que quanto maior o tempo na atividade menor a percepção de tais fatores. Este dado é relevante, já que para Glina (2010, p. 15), tais elementos relacionam-se aos "aspectos do desenho do trabalho e seus contextos sociais e ambientais, que têm potencial de motivar danos psicológicos e sociais ou físicos". Deste modo, sua percepção é fator colaborador para manter os aspectos psicológicos, sociais ou mesmos físicos sem danos no trabalhador.

Condições laborais decentes não se constituem em uma realidade na mineração informal, como apresentado nesta abordagem. Mediante os achados, necessário se faz o desenvolvimento de outros estudos capazes de contemplar a observação do lócus de 
trabalho, que busquem comparar o exercício e ambiente laboral de trabalhadores formais e informais, bem como mensurem os resultados por meio da aplicabilidade de ferramentas já usuais/validadas no campo da ergonomia. Esta nova abordagem trará mais do que as opiniões emitidas pelos próprios trabalhadores, marcadas por características e vivências pessoais.

\section{CONSIDERAÇÕES FINAIS}

Objetivou-se com esta pesquisa identificar os fatores ergonômicos, psicossociais e os riscos no trabalho informal do setor mineral do estado da Paraíba sob a percepção de mineiros. Diante dos achados, é possível asseverar que o mesmo foi alcançado, pois a totalidade dos trabalhadores, apesar de possuírem baixa escolaridade manifestou, em maior ou menor grau, os fatores ergonômicos, psicossociais e os riscos no seu ambiente laboral.

Conforme os mineiros informais, todos os riscos estão presentes na mineração, com destaque para os agentes físicos e químicos, o que alerta sobre a necessidade de novas práticas saudáveis no ambiente ocupacional. Contudo, a percepção de tais fatores difere em comparação com o sexo dos trabalhadores. Ainda, constatou-se que o tempo de trabalho e a idade foram características que interferiram significativamente no modo de perceber os fatores ergonômicos, psicossociais e os riscos ocupacionais.

Pelo exposto, contribuições para a ciência, academia e sociedade podem ter sido levantadas, já que a partir dos achados ações individuais e coletivas podem ser implementadas no setor. Inicialmente, estratégias de políticas públicas para o desenvolvimento e oportunização de melhores práticas parecem oportunas. É impreterível buscar intervir nos riscos ocupacionais presentes no processo de trabalho no setor mineral, especialmente o controle de ruídos (com medidas na fonte, no ambiente e no homem), pois são agentes capazes de implicar fortemente sobre o processo saúde-doença dos mineiros. De modo mais particular, realizar oficinas educativas contemplando os riscos ocupacionais e os aspectos ergonômicos do trabalho em prol de melhorias na apreensão do conhecimento são adequadas, bem 
como estimular a participação do trabalhador em ações e planos definidos para o gerenciamento dos riscos e a realização de exames periódicos (como a audiometria) são fundamentais.

Apesar das evidências, limitações decorrentes da pesquisa foram identificadas. Inicialmente, o fato de o instrumento de coleta de dados utilizado não ser validado. Também, viés de informação pode ter ocorrido nesta investigação, pois as percepções sofrem influência das vivências de cada mineiro. No mais, os dados coletados perpassam pela credibilidade das informações repassadas, bem como do estado físico e emocional dos pesquisados durante o levantamento das informações. Deste modo, alguns resultados podem não ter se apresentado objetivamente.

Isto posto e dado o grande e crescente número de trabalhadores inseridos na clandestinidade na ocupação na região, há a necessidade da área continuar avançando a partir de novos estudos, pois muita coisa precisa ainda de reflexão e mudanças.

\section{REFERÊNCIAS}

APUD, E. Ergonomics in mining: the Chilean experience. Hum Factors.,v. 54, n. 6, p. 901-7, 2012. http://hfs.sagepub.com/content/54/6/901

; MEYER, F. Factors influencing the workload of forest fire-fighters in Chile. Work, v. 38, n. 3, p. 203-9, 2011. http://dx.doi.org/10.3233/wor-2011-1124

ARANGO, H. G. Bioestatística teórica e computacional. 3. ed. Rio de Janeiro: Guanabara Koogan, 2009.

BRASIL. Conselho Nacional de Saúde. Resolução no 466/2012 que aprova as diretrizes e normas regulamentadoras de pesquisa envolvendo seres humanos. Publicada no DOU no 12, 13 de junho de 2013. Seção 1, p. 59.

. Ministério do Trabalho e Emprego. Norma regulamentadora no 4. Dispõe sobre os Serviços Especializados em Saúde e Medicina do Trabalho de 11 de dezembro de 2009. Diário Oficial da União de 14/12/2009. Disponível em: <http://www.feis.unesp.br/Home/cipa/nr-04--servicos-especializados-em-eng.-de-seguranca-e-em-medicina-do-trabalho.pdf>. Acesso em: 08 jul. 2014.

CAMARGO, D. A.; CAETANO, D.; GUIMARÃES, L. A. M. Psiquiatria ocupacional II: síndromes psiquiátricas orgânicas relacionadas ao trabalho. Disponível em:

$<$ http://www.unesp.br/costsa ses/mostra arq multi.php?arquivo=4250 > Acesso em: 25 jun. 2015.

Revista Produção Online, Florianópolis, SC, v.15, n. 3, p. 1099-1120, jul./set. 2015. 
CAVALCANTE, F.; FERRITE, S.; MEIRA, T. C. Exposição ao ruído na indústria de transformação no Brasil. Rev.CEFAC, v. 15, n. 5, p. 1364-70, 2013.

http://dx.doi.org/10.1590/S1516-18462013005000021

COSTA, A. O modo psicossocial: um paradigma das práticas substitutivas ao modo asilar. Coleção Loucura \& Civilização. Rio de Janeiro, editora Fiocruz, 2000.

COSTA, B. S.; REZENDE, E. N. Meio ambiente do trabalho e a saúde do trabalhador na mineração brasileira. Rev. Inst. Direito Bras., v. 1, n. 2, p. 759-92, 2012. Disponível em: <http://www.idb-fdul.com/uploaded/files/2012 020759 0792.pdf>. Acesso em: 06 jun. 2014.

COSTA, J. K. L. Levantamento dos problemas que afetam trabalhadores do pólo gesseiro: um estudo epidemiológico em Trindade - PE. 2012. 59f. Monografia [Graduação em Enfermagem] - Faculdade Santa Maria, Cajazeiras - PB, 2012.

, et al. Riscos ocupacionais e levantamento dos problemas que afetam trabalhadores de fábricas de gesso em Pernambuco. Revista Temas em Saúde, v. 14, n. 1, p. 175-91, 2014. DEPARTAMENTO NACIONAL DE PRODUÇÃO MINERAL (DNPM). Mineração na Paraíba. Disponível em: <http://www.dnpm.gov.br/default.asp>. Acesso em: 05 jun. 2013.

DÍAZ, J. M.; ABRIL, F. G. M.; GARZÓN, J. A. G. Salud y trabajo: minería artesanal del carbón en Paipa, Colombia. Av. Enferm., v. 28, n. 1, p. 107-15, 2010. Disponível em: $<$ http://www.revistas.unal.edu.co/index.php/avenferm/article/view/15660>. Acesso em: 05 jun. 2013.

ELENGE, M. M.; BROUWER, C. Identification of hazards in the workplaces of Artisanal mining in Katanga. Int J Occup Med Environ Health, v. 24, n. 1, p. 57-66, 2011.

http://dx.doi.org/10.2478/s13382-011-0012-4.

FALEIRO, F. F.; LOPES, L. M. Aspectos da mineração e impactos da exploração de quartzito em Pirenópolis-GO. Ateliê Geográfico, v. 4, n. 11, p.148-62, 2010. Disponível em:

<http://www.cprm.gov.br/publique/media/art quartzito Faleiro.pdf>. Acesso em: 06 jun. 2014.

FELIPE, G. Os acidentes nas minas de carvão da região carbonífera de SC (1980-2000): uma história silenciada pela ideologia do progresso e pelos órgãos de comunicação regional. 2013. 82 fls. Trabalho de Conclusão de Curso [Graduação em História]. Universidade do Extremo Sul Catarinense, Criciúma, 2013.

FERNANDES, R. C. P.; ASSUNÇÃO, A. A.; CARVALHO, F. M. Tarefas repetitivas sob pressão temporal: os distúrbios musculoesqueléticos e o trabalho industrial. Ciênc. Saúde Coletiva, v. 15, n. 3, p. 931-42, 2010. http://dx.doi.org/10.1590/S1413-81232010000300037

GANIME, J. F., et al. O ruído como um dos riscos ocupacionais: uma revisão de literatura.

Enferm. glob. [online], n. 19 p. 1-15. 2010. Disponível em:

<http://scielo.isciii.es/pdf/eg/n19/pt revision1.pdf>. Acesso em: 12 out. 2014.

GLINA, D. Modelos teóricos de estresse e estresse no trabalho e repercussões na saúde do trabalhador. In: GLINA, D.; ROCHA, L. E. (Org.). Saúde mental no trabalho: da teoria à prática. São Paulo: Roca, 2010. p. 3-30.

Revista Produção Online, Florianópolis, SC, v.15, n. 3, p. 1099-1120, jul./set. 2015. 
HIRATA, H. A precarização e a divisão internacional e sexual do trabalho. Sociologias, v. 1, n. 21, p. 24-41, 2009. http://dx.doi.org/10.1590/S1517-45222009000100003

IGUTI, A. M.; HOEHNE, E. L. Lombalgias e trabalho. Rev. bras. saúde ocup., v. 28, n. 107-08, p. 73-89, 2003. http://dx.doi.org/10.1590/S0303-76572003000200007

IGWE, O., et al. Risks associated with the mining of $\mathrm{Pb}-\mathrm{Zn}$ minerals in some parts of the Southern Benue trough, Nigeria. Environ Monit Assess, v. 186, n. 6, p. 3755-65, 2014. http://dx.doi.org/10.1007/s10661-014-3655-3

INSTITUTO BRASILEIRO DE GEOGRAFIA E ESTATÍSTICA (IBGE). Ministério do Planejamento, Orçamento e Gestão. Comissão Nacional de Classificação. Classificação Nacional de Atividades Econômicas - Versão 2.0. Estrutura detalhada e notas explicativas. Rio de Janeiro: IBGE, 2007.

KOROLIJA, N.; LUNDBERG, J. Speaking of human factors: emergent meanings in interviews with professional accident investigators. Saf Scienc., v. 48, n. 1, p. 157-65, 2010. http://dx.doi.org/10.1016/i.ssci.2009.07.004

KREUZER, M., et al. Silica dust, radon and death from non-malignant respiratory diseases in German uranium miners. Occup Environ Med., v. 70, n. 12, p. 869-75, 2013. http://dx.doi.org/10.1136/oemed-2013-101582

KUNDA, R.; FRANTZ, J.; KARACHI, F Prevalence and ergonomic risk factors of work-related musculoskeletal injuries amongst underground mine workers in Zambia. J Occup Health, v. 55, n. 3, p. 211-7, 2013. http://dx.doi.org/10.1016/j.berh.2014.07.006

LENNÉ, M. G., et al. A systems approach to accident causation in mining: an application of the HFACS method. Accid Anal Prev., v. 48, p. 111-7, 2012.

http://dx.doi.org/10.1016/i.aap.2011.05.026

LIU, Y., et al. Exposure-response analysis and risk assessment for lung cancer in relationship to silica exposure: a 44-year cohort study of 34,018 workers. Am J Epidemiol., v. 178, n. 9, p. 1424-33, 2013.

MARTINS, J. T. et al. Significados de carga de trabalho para enfermeiros de pronto socorro/emergência. Cienc. Cuid Saúde, v. 12, n. 1, p. 40-6, 2013. http://dx.doi.org/10.1590/S0103-21002013000100011

MAURO, M. Y. C., et al. Condições de trabalho da enfermagem nas enfermarias de um hospital universitário. Esc Anna Nery Rev Enferm., v.12, n. 1, p. 13-8, 2010. Disponível em:

<http://www.scielo.br/pdf/ean/v14n2/05.pdf>. Acesso em: 12 out. 2014.

MCPHEE, B. Ergonomics in mining. Occup Med., v. 54, n. 5, p. 297-303, 2004. http://dx.doi.org/10.1093/occmed/kgh071 
MOTTER, A. A.; SANTOS, M.; GUIMARÃES, A. T. B. O que está a sombra na carga de trabalho de estivadores? Revista Produção On Line, v. 15, n. 1, p. 321-44, 2015. http://dx.doi.org/10.14488/1676-1901.v15i1.1845

MOULIN, M. G. B.; MORAES, A. B. T. Vamos fazer poeira: fontes e expressões da pressão no trabalho do setor de rochas ornamentais no Espírito Santo. Rev. Bras. Saude Ocup., v. 35, n. 122, p. 192-200, 2010. http://dx.doi.org/10.1590/S0303-76572010000200003.

NEGRI, A. C. G. Exposição a materiais biológicos: acidentes de trabalho atendidos em Hospital Universitário de Campo Grande/MS. Dissertação (Mestrado em Programa de PósGraduação em Saúde e Desenvolvimento) - Universidade Federal do Mato Grosso do Sul. Campo Grande: UFMS, 2012.

NERY, A. A.; ALVES, M. S. A relação do processo saúde-doença e o trabalho na mineração. J Health Scilnst.. v. 29, n. 4, p. 269-71, 2011. Disponível em: <http://www.unip.br/comunicacao/publicacoes/ics/edicoes/2011/04 outdez/V29 n4 2011 p269-271.pdf>. Acesso em: 06 jun. 2014.

PASCAUD, G., et al. Environmental and health risk assessment of $\mathrm{Pb}, \mathrm{Zn}, \mathrm{As}$ and $\mathrm{Sb}$ in soccer field soils and sediments from mine tailings: solid speciation and bioaccessibility. Environ Sci Pollut Res Int., v. 21, n. 6, p. 4254-64, 2014. http://dx.doi.org/10.1007/s11356-013-2297-2

PATTERSON, J. M.; SHAPPELL, S. A. Operator error and system deficiencies: analysis of 508 mining incidents and accidents from Queensland, Australia using HFACS. Accid Anal Prev., v. 42, n. 4, p. 1379-85, 2010. http://dx.doi.org/10.1016/j.aap.2010.02.018

PIERANTONI, C. R., et al. Carga de trabalho de um profissional típico da atenção primária em saúde no Brasil: os agentes comunitários de saúde. Rev. APS., v. 14, n. 4, p. 490-6, 2011. Disponível em: <http://www.obsnetims.org.br/uploaded/22 $12014 \quad 0$ Carga de trabalho ACS.pdf >. Acesso em: 06 jun. 2014.

PIOVAN, R. Resiliência: como superar pressões e adversidades no trabalho. São Paulo: Reino Editorial, 2010.

PONTES, H. A incidência da lombalgia em indústria de fundição: um estudo de caso sob a ótica da ergonomia. 2005.137 f. Dissertação [mestrado em Engenharia de Produção] -

Programa de Pós-Graduação, Universidade Tecnológica Federal do Paraná, Campus de Ponta Grossa, 2005.

RODRIGUES, P. P., et al. Análise do nível de ruído em equipamentos da construção civil na cidade de Curitiba. Revista Produção On Line, v. 9, n. 3, p. 466-88, 2009.

http://dx.doi.org/10.14488/1676-1901.v9i3.234

ROUQUAYROL, M. Z.; GURGEL, M. Epidemiologia e saúde. 7 ed. - Rio de Janeiro: Medbook, 2013.

RUIZ, V. S.; ARAÚJO, A. L. L. Saúde e segurança e a subjetividade no trabalho: os riscos psicossociais. Rev. bras. Saúde ocup., v. 37, n. 125, p. 170-80, 2012.

http://dx.doi.org/10.1590/S0303-76572012000100020

Revista Produção Online, Florianópolis, SC, v.15, n. 3, p. 1099-1120, jul./set. 2015. 
SANTO, A. F. E.; PAULA, J. A.; PEREIRA, O. A. V. Percepção de trabalhadores de uma indústria têxtil sobre os riscos de seu ambiente de trabalho. Rev. Enferm. Integr., v. 2, n. 1, p. 188-99, 2009. Disponível em: $<$ http://www.unilestemg.br/enfermagemintegrada/artigo/v2/Orcione pereira Aline espirito santo e Janine de paula.pdf>. Acesso em: 06 jun. 2014.

SARAIVA, L. A. S.; FERREIRA, J. A.; COIMBRA, K. E. R. Relações de trabalho em empresas terceirizadas sob a ótica dos trabalhadores: um estudo no setor de mineração. RGO, v. 5, n. 2, p. 134-48, 2012. Disponível em: <http://bell.unochapeco.edu.br/revistas/index.php/rgo/article/view/1393/773>. Acesso em: 15 jun. 2014.

SEIDLER, A., et al. Dinitrotoluene exposure in the copper mining industry and renal cancer: a case-cohort study. Occup Environ Med., v. 71, n. 1, p. 259-65, 2014.

http://dx.doi.org/10.1136/oemed-2013-101850

SKANDFER, M., et al. A. How occupational health is assessed in mine workers in Murmansk Oblast. Int J Circumpolar Health, v. 71, n. 0, p. 1-8, 2012.

http://dx.doi.org/10.3402/ijch.v71i0.18437

SOLARI, G.; REYES, J.; SOLARI, B. Contribución a la ergonomia desde el análisis de la condición física en una muestra de trabajadores mineros con/sin síndrome de dolor lumbar (Región de Antofagasta, Chile). Rev. Cienc. Salud., v. 13, n. 1, p. 16-32, 2009.

SOUSA, M. N. A.; ALCHIERI, J. C. Atenção a saúde do trabalhador no processo de produção de caulim: uma revisão integrativa da literatura. C\&D-Revista Eletrônica da Fainor, v. 4, n. 1, p. 20-37, 2011.

, et al. Ergonomic in mining: contribution for worker health promotion. Fiep Bulletin, v. 84, Special Edition, p.1-7, 2014.

STEFANESCU, L.; ROBU, B. M.; OZUNU, A. Integrated approach of environmental impact and risk assessment of Rosia Montana Mining Area, Romania. Environ SciPollut Res Int., v. 20, n. 11, p. 7719-27, 2013. http://dx.doi.org/10.1007/s11356-013-1528-x

STUCKLER, D., et al. Introduction: 'dying for gold': the effects of mineral miningon HIV, tuberculosis, silicosis, and occupational diseases in southern Africa. Int J Health Serv., v. 43, p. 4, p. 639-49, 2013. http://dx.doi.org/10.2190/HS.43.4.C

VASCONCELOS, S. C. S.; VASCONCELOS, C. I. S.; MORAES NETO, J. M. Riscos ambientais causados na extração mineral: estudo de caso em uma mineração à céu aberto. Polêm!ca, v. 12, n. 4, p. 821-9, 2013. Disponível em: <http://www.epublicacoes.uerj.br/index.php/polemica/article/view/8651/6609 >. Acesso em: 26 jun. 2014.

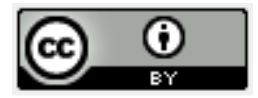

Artigo recebido em 19/03/2015 e aceito para publicação em 25/06/2015 DOI: http://dx.doi.org/ 10.14488/1676-1901.v15i3.2018

Revista Produção Online, Florianópolis, SC, v.15, n. 3, p. 1099-1120, jul./set. 2015. 